\title{
Positive Psychologists on Positive Psychology: Acacia Parks
}

\author{
Interview by \\ Aaron Jarden
}

\begin{abstract}
Acacia Parks is an assistant professor of psychology at Hiram College and completed her PhD with Martin Seligman at the University of Pennsylvania. Acacia's area of expertise is in positive interventions and applying positive psychology using new technologies.
\end{abstract}

\section{What prompted you to become interested in positive psychology?}

My interest was a marriage between my original interest and my advisors' interests. It grew from first talking to Marty Seligman about research ideas when I was still applying for graduate school, and conversations with a couple of prospective research advisors. Whenever you're starting graduate school there is a compromise between what you're interested in, and what your advisor is interested in. I came in with an interest in preventing depression using cognitive therapy. I thought that that was a really cool model instead of treating. By the time I had talked to Marty about that, the positive psychology thing was just starting to gear up and he was beginning to think about this positive intervention idea. He suggested to me that cognitive therapy stuff for prevention was not really where the future was headed, and what we're going to do instead is this wellness approach, this improving wellbeing. That's going to do the same thing, only better; and that really resonated with me, it sounded really promising because one of the problems that they had with CBT was that people struggle with it, especially if you're not depressed already. Why would you do all this difficult stuff for depression? It wasn't really compelling to people in the way that happiness is. So, we started talking about positive interventions and it all just blossomed from there. We developed this manual, and everything I've done has been steps beyond that.

\section{So your area in positive psychology, would you describe it as positive interventions?}

Yes, totally.

\section{And how long have you been working in this area?}

Since I started graduate school, which was in 2003.

In general terms, in your mind, what are some of the distinctive features of positive psychology?

I think about positive psychology as being split into a basic theory and then applied sections. There are some really fundamental areas, like [Barbara] Frederickson's positive emotion research, where 'I can think of applications but that's not the purpose of the research'; the 
research is 'We want to understand the function that emotions serve'. Areas like that are basic science contributions. [Shelly] Gables' work about relationships has been translated into interventions, but it's about relationship processes, not interventions. They did not do that research seeking to come up with an application. Areas like that, I feel, are a more theoretical piece. On the other hand, there's this more applied piece where we say, 'What's the outcome we want?' and 'How can we work backwards to figure out how to best do that?'; and that's where the positive intervention research comes in. Also, things like coaching and workplace situations and trying to change organizations fit in that applied sector. So I see positive psychology as having those two areas.

A lot of fields have that kind of split, though, so it's not really what makes positive psychology distinctive. What's really unique about positive psychology is the interplay between researchers - both basic and applied-and practitioners. Unlike clinical psychology, which is broken in half and has been trying for decades to bridge the 'gap between science and practice,' our practitioners want very much to do what is research-based. They are a huge asset to us. I think they could be even more of an asset if we (researchers) spent more time talking to them and learning from them. But yeah, if you look at various subfields of psychology, I'm not sure you'll find any other area where practitioners are so eager to learn more about the science, and to put science into practice.

\section{When you think of the big questions that positive psychology addresses, what are the questions that stand out to you?}

That's a really interesting question, because in some ways I see that there is no difference from other areas of psychology that are trying to change behavior. Of course, I'm biased because I'm an intervention researcher. I think about positive psychology and then I think about the applied half, because that's the half that I work in, but to me it's about 'How do you get a person to change their behavior?', which I think is applicable to therapy research, health psychology and to a variety of parts of psychology. It's not unique to positive psychology. What's new and different are the outcomes we are interested in, and the specific behaviors we are trying to change. But a lot of it is just, 'How do you get something to stick?', 'How do you get people to change their ideas?', and that flows through social psychology and other areas as well. But I do think that those are the central questions.

\section{What do you think are some of the most valid criticisms that the field of positive psychology faces to date?}

One thing I worry about is the rate at which things become applied. I remember when we first started talking about positive interventions in the popular media in 2004 and those things started to get published. Those things were already getting used out in the world. For example, coaches were using them, people were hearing about them in the news and using them, and we just had this one study. But that's just how it seems to go, it's very fast moving, and the second that news gets out that something is helpful in a single study, it's all over the place. On one hand that's really cool, because it's getting out there, but on the other hand, it's a little worrisome because you wonder 'What if there's a mistake in the data analyses?', or if this was just a funny sample that doesn't replicate. It's already out there. It's too late by then. So I worry about that a little bit, more so than in fields like clinical psychology, which I think may be overly cautious and overly slow to get things out there. Things get out here even faster than you can keep hold of them. People who argue about that have a valid point, especially when it 
comes to research findings that are lost in translation somewhat. One critique that positive psychology gets a lot from people like [Barbara] Ehrenreich and James Coyne is that positive psychologists tell people with cancer that they should just 'buck up' and that they should just be optimistic and they'll do better. I don't know anyone who actually says that, but what happens is that it gets out there to the popular media and misunderstood and mistranslated. Then, all of a sudden, that is what positive psychology is saying to a good number of people. So I think in some ways we're not as careful as we could be about the sound bites that we release into the ether, or about maintaining the integrity of those sound bites so that they are accurate. What happens is that people like Barbara Ehrenreich hear something that just isn't what we're saying, but by the time it gets to her it is, if that makes sense. So I think that there are definitely some messages from positive psychology that reach the general public that aren't what we intended; and those messages, even though they are not the intended messages, may be harmful. I think that this is a valid criticism.

\section{What is your view on the relationship between a positive intervention and assessing the effectiveness of these interventions over time? I mean there are a lot of people doing interventions but not everyone is assessing whether they are working or not. What are your thoughts about that?}

In some sense, I'm always surprised when practitioners aren't assessing whether something is working, even just within their practices. For example, when I did clinical training as a graduate student (I'm not a clinician, but I started off as one), every time we saw a client they took assessment measures. Next time we saw them they took more assessment measures, so we were constantly checking to make sure that we were actually doing something. I know that that is a practice that a lot of practitioners use, but then I also know that there are practitioners who don't. That's effectiveness on a much smaller scale, but equally important. If you're taking something that's manualized and you're trying to implement it in the real world, you want to make sure it's working in your setting. You should check, you shouldn't just assume that because the research says it's going to work it will. But at the same time, you shouldn't assume that the research is invalid and not even try using it in your setting, which is another thing that practitioners can do sometimes, in that they figure that this is not relevant to me, this wasn't tested on my population. Researchers and practitioners are both falling down on their responsibilities in terms of getting everything to the practitioners in a digestible way. But then there are also the practitioners being concerned with efficacy and understanding that there is literature out there that shows that judgment and intuition are not perfect, that they are flawed; so if you think that this is working because I think that it is working, that doesn't always match up.

\section{What's one aspiration you've got for the field of positive psychology? In five years from now, how would you like to see the field of positive psychology?}

I would like to see some way to get the general public to care about the difference between something that is empirically validated and something that is not. Because right now I think that people are just as happy to read The Secret as they are to read The How of Happiness. Each of these is not like the other, but to the general public they are all grouped in the same category: books about happiness. Part of the onus of this is on us not to do research and then write a book and put it out into the ether and assume that that works, but to actually test the books. Test the things that we are putting out there up against quackery and show that they are better, so that eventually the idea can get out to the general public that yes, there are lots of choices. 
For example there is Tony Robbins, and he's going to tell you how to get happier, and there is The Secret, which says that if you think about being happy suddenly the world will attract happiness to you: and those ideas are not like what we are doing. We need some way to get the general public to be more discerning about that, so that they can tell the difference about something that's tested and something that someone just made up one day. That would just be superb.

\section{What do you think is going to be the next hot topic for positive psychology over the coming few years?}

I know what I would like the new hot topic to be! One of the conference talks I've just heard was looking at how physiological measures may be an alternative to self-reporting. I'd really like to see an emphasis on measures other than self-report, which has been used in psychology for a long time. But the problem is that nobody has a viable replacement for it and it's very cumbersome to do anything other than self-report. What I would love to see are methods that aren't cumbersome, and that are alternatives to self-report. For example, wrist bands that measure your level of stress so you don't have to ask a person how stressed out they were this last week, because you have aggregate data to show you how stressed out they were; and it's not done with cortisol, because measuring cortisol levels is expensive. These other physiological measures we were unable to use because they were prohibitive in cost. An alternative can be a thing you can buy upfront, and put on your participants, and it doesn't have on-going expense. So I would really love to see a move towards methods that assess happiness in a way that doesn't alienate the economists because it's not a hard outcome, it doesn't alienate the medical people because it's not a hard outcome either, but something that feels more real than self-reported happiness. I feel like this will not only strengthen the field because it will also address the criticism that people get really upset at the idea of self-reported happiness, but it will also help us learn a lot more about what we're actually doing for people, what it actually means when we change their self-reported happiness. Does that mean we're changing their moment-to-moment happiness or just their retrospective evaluations of their lives? We can learn so much more from that kind of moment-to-moment data collection instead of retrospective self-report, which we know from a lot of researchers is totally flawed. I'd really like to see a movement towards more sophisticated data. We're better than self-report, we just haven't figured out how we want to be better than self-report yet.

\section{Who do you look up to in the field of positive psychology?}

I have got a lot of really excellent advice from Shane Lopez, who has edited numerous volumes, and as I have tried to move towards that myself, he just always has such sage wisdom. Shane has been supportive, even when he barely knew me, when I was just becoming a graduate student. He has continued to be very supporting, knowledgeable and accessible. Sonja Lyubomirsky is another leader in the field who has been so supportive of me from the very beginning of my career. She has been a great mentor over the years. She got me started as a reviewer at the Journal of Positive Psychology and nudged me towards Associate Editorship. More recently, Sonja has been a great collaborator, too, and has graciously found time to contribute to both of my edited books. It takes a special kind of person to spend so much time and energy on someone who isn't their own student. I am constantly grateful for her. The other person I really admire is Ed Diener, who is actually the epitome of positive psychology. He's happy, he's energetic, he's curious, he's engaged, he's supportive, and he's personable. Ed 
Diener is to me a paragon, he is a truly happy person and something about interacting with him is a very lively and inspiring experience.

\section{Who do you think are the other young emerging researchers who are doing great things?}

I think by now that people generally know Todd Kashdan. Even though he's not the old guard, he's a whippersnapper who's making noise and good trouble. What I love about Todd is that he's got balls of steel; he's brave and oppositional, in just the way that the field needs. There's such a strong status quo in any field, everyone is doing things their own way, then there's Todd, who just comes along and goes 'No, No, not that way, this way, or some other way'. He gets people to think in a way that I really respect. I always try to get Todd involved in anything that I do. For example if I'm in a symposium I always think, let's get Todd in here and see what he has to say because I think that this is really great, but I'm sure that there's something that I haven't thought of and Todd has always thought of something that I haven't. I'm also a big fan of Michelle Louis. She recently published a paper suggesting that talking about strengths as a fixed personality trait might make people less willing to work on them, figuring they are stable so what's the point. Very cool stuff. We need more people adding nuance to positive intervention research. Not just, 'do they work?' but 'when do they work and for whom?' and 'when might they backfire?'.

\section{What are your plans for the future?}

I just started in a new tenure track position, so I'm getting my lab settled and spending my startup and just trying to figure out what I'm going to be doing for the next few years. I'm really interested in this physiological measurement thing, so I'm hoping to drop some money on that and I'm also hoping to be doing ambulatory assessment-that's the new fancy term for 'experience sampling' - research. I think that's the direction we're headed in as a field. I'm hoping to establish myself there and I also have these teaching projects that I'm working on, for example, an edited book with positive psychology activities that's going to be completed at the end of this summer. I'm hoping to continue along that line. For example, I am guest editing a special issue for the Journal of Positive Psychology on 'positive psychology and higher education' - that's a passion of mine. I've been teaching positive psychology since I started in graduate school. That's eight years now. I've taught positive psychology a lot and it's always my favorite course to teach and I really like helping other people learn to teach it and mentor people in that area. So, I hope to continue that in addition to the research.

\section{For someone new to the field of positive psychology, what is one book that you would recommend they read first?}

Although it's an old standard, I really recommend the Handbook of Positive Psychology. It's been around since 2003 I think, and they have a new edition so it's updated, but no book provides, for a researcher, a better basis in a really broad array of topics, and a great orientation to who is doing the lead research. For people interested in positive interventions in particular, I am working on a Handbook of Positive Interventions that should be coming out in late 2012. I'm really excited about it. It's got a nice line-up of contributors.

\section{What about for someone who's not a researcher?}

For the general public, The How of Happiness would provide the best overview. There are other good books, for example Curious, but that is very specific. And Authentic Happiness is a great 
book, but it is very theoretical. The How of Happiness is a perfect mix of research summary that's clear and digestible, and also actual techniques and things that people can try. Reading them in that way is very helpful because it shows the things that researchers are having people do - this is what we mean by increasing happiness. So that is really nice. I always have my positive psychology students read The How of Happiness because it's such a good introduction to the field.

So your area of expertise is positive psychology interventions. If someone comes to you and says they want to be happier, which ones would you suggest?

It depends on the context. I've been consulting on this grant by Chris Kahler at Brown and he's adapting positive psychotherapy for smoking cessation. One of the things that they do in smoking cessation is start the intervention two weeks before they actually quit. One of the things they are trying to do in this intervention is frontload with a lot of positive emotion because positive emotion is a predictor of good outcomes. So they are trying to make people experience as much positive emotion as possible so they have this protective factor when they are trying to quit that's going to predict their success. There are a couple of exercises in that situation where it seems really logical that they should start with that, for example, the gratitude visit has been demonstrated to have a very powerful but temporary effect, so if what you're looking for is an immediate benefit to get a person moving, then the gratitude visit is a good choice because it's very intense. But as a long-term technique the gratitude visit is not a good choice because it is not very reusable and its effects are lost very quickly. I recommended that and I also recommended 'three good things', which has a low-grade, but more sustained, benefit. So what they did was start with 'three good things'. It takes a while for that to build up, but once it does, it is a sort of constant source of positive emotion. Combine that with the gratitude visit so that you have an immediate increase from the gratitude visit and, by the time that's faded, 'three good things' has picked up and will carry it in the longer term. They have different strengths as activities: one is more on-going and sustained and is effective but takes time, but in the time that it takes you can be doing this other activity that keeps the person interested and engaged. I think that those are examples of two activities that are helpful to most people. The other activities involve a lot more nuance and consideration of which is best for whom. But any time that I think of a prototypical positive intervention that I want people to stick with I think of those two as a place to start.

\section{Is there anything that you would like to comment on in general that you think would be useful for somebody who doesn't know about positive psychology and who is reading a book about positive psychology to find out a bit more?}

There are a lot of misconceptions about positive psychology. As somebody who has taught not just a positive psychology course, but also these freshman writing seminars on the topic of happiness, I've had a lot of exposure to the things people think about happiness, and a lot of these are very disturbing to me. One of these includes misconceptions about optimism. People think that it is great to be positive all the time, and that that is what optimism is; but there is so much more nuance to what optimism is as a concept, so much more than just thinking everything is going to work out all the time. What I try to explain to people is that optimism is much more about entertaining the possibility that things could work out. So, if you're a pessimist you think that things are not going to work out, and then you don't even bother, so of course it doesn't work out because you didn't try. But optimism is just keeping open the idea that it could work and trying, as if it will work, so that you maximize your chances of it 
working. That's the reason that optimists are more successful. It's not magic, it's effort, and your level of effort depends on what you expect. So maybe optimists are wrong some of the time because they might think that something is possible when it's not; but people worry about there being some danger to that, like 'Oh what if they're deluded, you know, they think that everything's going to go right and then they're lazy and they don't do anything'. That's not what happens at all. People who don't do anything are the pessimists who think that it's not going to work out in the first place. Optimism is a really good example of something that just got lost in translation. Everyone in positive psychology understands what it is and outside of positive psychology it became this 'think positive' mantra, which is not at all what optimism is.

The other thing I think that people really misinterpret, going back to the earlier positive psychology and cancer example, is just because there are research findings that suggest that outlook affects your health, doesn't mean that you should be telling people that they are responsible for what happens. There is such a difference in saying that something is predictive and telling somebody what they should do. Marty Seligman and others constantly say that we're not prescribing, but people want prescriptions and people take prescriptions away. It's in some ways on us to be careful about what we say because it will be made into a prescription no matter what. I think that the solution to that is not to refuse to make prescriptions, but to control the direction of the prescriptions. For example, if you're going to report that people who have a more optimistic outlook survive cancer for longer, you should not say, 'But there's no prescription here, I'm just describing'. Somebody else is going to make up the prescription and then it could be wrong. If you're going to throw that idea out there, then in a way it's your responsibility to harness it so the take home message is something that isn't harmful. For example, in this situation the take home message might be, 'If the person is coping well, don't tell them that they are wrong'. Bonnano has all this research about how people get a bad rap when somebody dies and they're not doing poorly, for example when someone loses a spouse and they're relieved because their spouse is out of pain, or because they were older, or had a disease, and they're doing alright because they're coping well, then people say, 'You're making a mistake and you must secretly be upset and you're not expressing it', and people get all this social flack for that. So it might be, in the cancer case, that you don't give people flack if they're doing alright. It's possible to do alright and it's acceptable to do alright. There's no evidence for this idea that you need to do 'grief work', or that you have to be upset. There's no evidence that it will come back to bite you if you don't express some underlying distress. So, I think that you can turn that into a reasonable take home message that isn't harmful to people. My recommendation is that people take control of that by doing it themselves.

\section{Author}

Aaron Jarden

Open Polytechnic of New Zealand

aaron.jarden@openpolytechnic.ac.nz 